\title{
Comment on "Referral of young children to dental personnel by primary care nurses"
}

Article in International Journal of Dental Hygiene · February 2017

DOI: $10.1111 /$ idh. 12271

CITATIONS

0

4 authors, including:

\section{Reneé Pereyra-Elías}

Universidad Peruana de Ciencias Aplicadas (UPC)

38 PUBLICATIONS 138 CITATIONS

SEE PROFILE

Some of the authors of this publication are also working on these related projects:

Project

Profile and professional expectations of medical students from 11 Latin American countries View project 


\section{Comment on "Referral of young children to dental personnel by primary care nurses"}

\section{Dear Editor,}

We have read with interest the article "Referral of young children to dental personnel by primary care nurses" by Wigen and Wang. ${ }^{1}$ The authors share their positive experience with primary care nurses as an entry to the dental health system. However, we would like to comment a specific topic that specially caught our attention.

The authors state that the primary care nurses referred the patients to the dentist when there were evident caries lesions, visible plaque or high risk of developing this disease. ${ }^{1}$ Nevertheless, that clinical scenario is probably compatible with an established disease. Noncavitated lesions may not be evident without adequate equipment and to the eye of a non-specialist. ${ }^{2}$ Thus, primary healthcare services must include referral to dental practitioners also in the case of apparently healthy children without a dental consultation in the previous 6 or 12 months (according to the health system and availability of resources). A mixed clinical and radiological approach is recommended to detect this early stage of the disease both in primary and permanent teeth. ${ }^{2}$ Consequently, as it is well known, on-time diagnosis allows to stop caries progression to cavitation and pulpal involvement. ${ }^{3}$

To sum up, caries-preventive approaches must ensure referral to dental care of every patient who has not been to regular dental consultation in the previous 6-12 months in order to rule out non-evident lesions. We acknowledge the good efforts of the Norwegian health system and their primary care nurses. We encourage other countries to implement similar strategies.

\section{CONFLICT OF INTEREST}

The authors declare that they have no conflict of interests.

\author{
L Maccha $^{1}$ \\ $\mathrm{H}_{\text {Montenegro }}{ }^{1}$ \\ S Caballero-García ${ }^{1}$ \\ R Pereyra-Elías ${ }^{2}$ iD \\ ${ }^{1}$ School of Dentistry, Universidad Peruana de Ciencias \\ Aplicadas, Lima, Perú \\ ${ }^{2}$ School of Medicine, Universidad Peruana de Ciencias \\ Aplicadas, Lima, Perú \\ Email: renee.pereyra.elias@gmail.com
}

\section{REFERENCES}

1. Wigen TI, Wang NJ. Referral of young children to dental personnel by primary care nurses. Int J Dent Hygiene. 2016;DOI: 10.1111/idh.12238. [In press].

2. Kühnisch J, Ekstrand KR, Pretty I, et al. Best clinical practice guidance for management of early caries lesions in children and young adults: an EAPD policy document. Eur Arch Paediatr Dent. 2016;17:3-12.

3. Lee GH, McGrath C, Yiu CK. Developing clinical practice guidelines for caries prevention and management for pre-school children through the ADAPTE process and Delphi consensus. Health Res Policy Syst. 2016;14:44. 